\title{
Nomogram for calculation of left ventricular volumes
}

\author{
FRANKLIN B. SAKSENA AND G. B. SAKSENA \\ From Cardiac Catheterization Laboratory, Cook County Hospital, Chicago, Illinois; and Lockheed \\ Space and Missile Co., Sunnyvale, California, U.S.A.
}

A nomogram has been devised for the rapid derivation of left ventricular volumes from single-plane angiograms obtained in the $30^{\circ}$ right anterior oblique projection. The left ventricular volumes are derived from the use of the area-length formula of Dodge. The computed left ventricular volumes may then be adjusted to correspond to the actual volumes by an appropriate conversion chart.

Single-plane cineangiography in the right anterior oblique projection has been proposed as a technically easier method of obtaining the left ventricular volume than biplane angiography (Kasser and Kennedy, 1969; Snow et al., 1969; Kennedy et al., 1970). This paper presents a nomogram for the rapid derivation of the left ventricular volume from the right anterior oblique angiogram using a modified area-length formula of Dodge et al. (1960). It is hoped that this nomogram will prove useful in those medical centres where computers and light-pen writers might not be readily available. This nomogram could also serve as an independent means of rapidly performing or rechecking a large number of calculations involving corrected left ventricular volumes.

\section{Principle}

\section{(a) CALCULATION OF LEFT}

VENTRICULAR VOLUME

The principle of the nomogram (Fig. 1) is based on

the formula of an ellipsoid: $V^{\prime}=4 / 3 \pi \mathrm{abc}$, where

$\mathrm{V}^{\prime}=$ volume in $\mathrm{cm}^{3}$

$\mathrm{a}=$ semi-major axis $=$ one half length from apex to middle of aortic valve $=1 / 2 \mathrm{~L} \mathrm{~cm}$.

$\mathrm{b}=$ semi-minor axis in right anterior oblique view (cm).

$\mathrm{c}=$ other semi-minor axis at right angles to $\mathrm{b}$ (not seen in right anterior oblique view).

If it is assumed that the left ventricle is shaped like a prolate spheroid (Dodge et al., 1960) then $\mathrm{b}=\mathrm{c}$ and $\mathrm{V}^{\prime}=4 / 3 \pi \mathrm{ab}^{2} \ldots$ (1)

The projection of a prolate spheroid in $30^{\circ}$ right anterior oblique view is assumed to be an

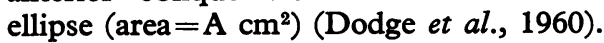

Then $\mathbf{A}=\pi \mathrm{ab} \ldots$. (2)

Received for publication 20 September 1976
Substituting for $b$ in (1) from (2) and letting $L=2 a$

$$
\text { we get } V^{\prime}=\frac{0 \cdot 848 A^{2}}{L} \ldots \text { (3) }
$$

The volume $\mathrm{V}^{\prime}$ from equation 3 is then adjusted for the magnification of the $x$-ray film by using a linear correction factor $M(\geqslant 1)$ where $1 \mathrm{~cm}$ true length $=M \mathrm{~cm}$ on $x$-ray film as viewed or projected. Hence the computed volume $\mathrm{V}$ becomes

$\mathrm{V}=\frac{0 \cdot 848 \mathrm{~A}^{2}}{\mathrm{LM}^{3}} \ldots$

Equation (4) was used to compute the volume (enddiastolic or end-systolic) depicted in the nomogram in Fig. 1.

This computed volume $\mathrm{V}$ can be adjusted to correspond to the actual left ventricular volume (V corr) as determined by models and postmortem left ventricles of known volumes (Dodge 1971), using the Dodge equation

$\mathrm{V}_{\text {corr }}=0.81 \mathrm{~V}+1.9 \ldots$ (5).

The value of $\mathrm{V}_{\text {corr }}$ corresponding to $\mathrm{V}$ can then be read directly from the conversion scale $V-V_{\text {corr }}$ on the extreme right-hand side of the nomogram.

\section{Application}

TO FIND LV VOLUME (RIGHT ANTERIOR

OBLIQUE VIEW) (Fig. 2)

With the sharp point of a pencil, mark the length on line $L$ and the magnification factor on line $M$. Join these two points with a straight line to cross the unscaled line G. By joining the point so obtained on line $G$ and the planimetered area on line $A$ a straight line may be extended to meet line $\mathrm{V}$ yielding the volume $\left(\mathrm{cm}^{3}\right)$.

If a grid is used to obtain the magnification factor where $1 \mathrm{~cm}^{2}$ actual area corresponds to $M^{2} \mathrm{~cm}^{2}$ $x$-ray distorted area (i.e. $\mathrm{M}^{2}=x$-ray distorted area/ 

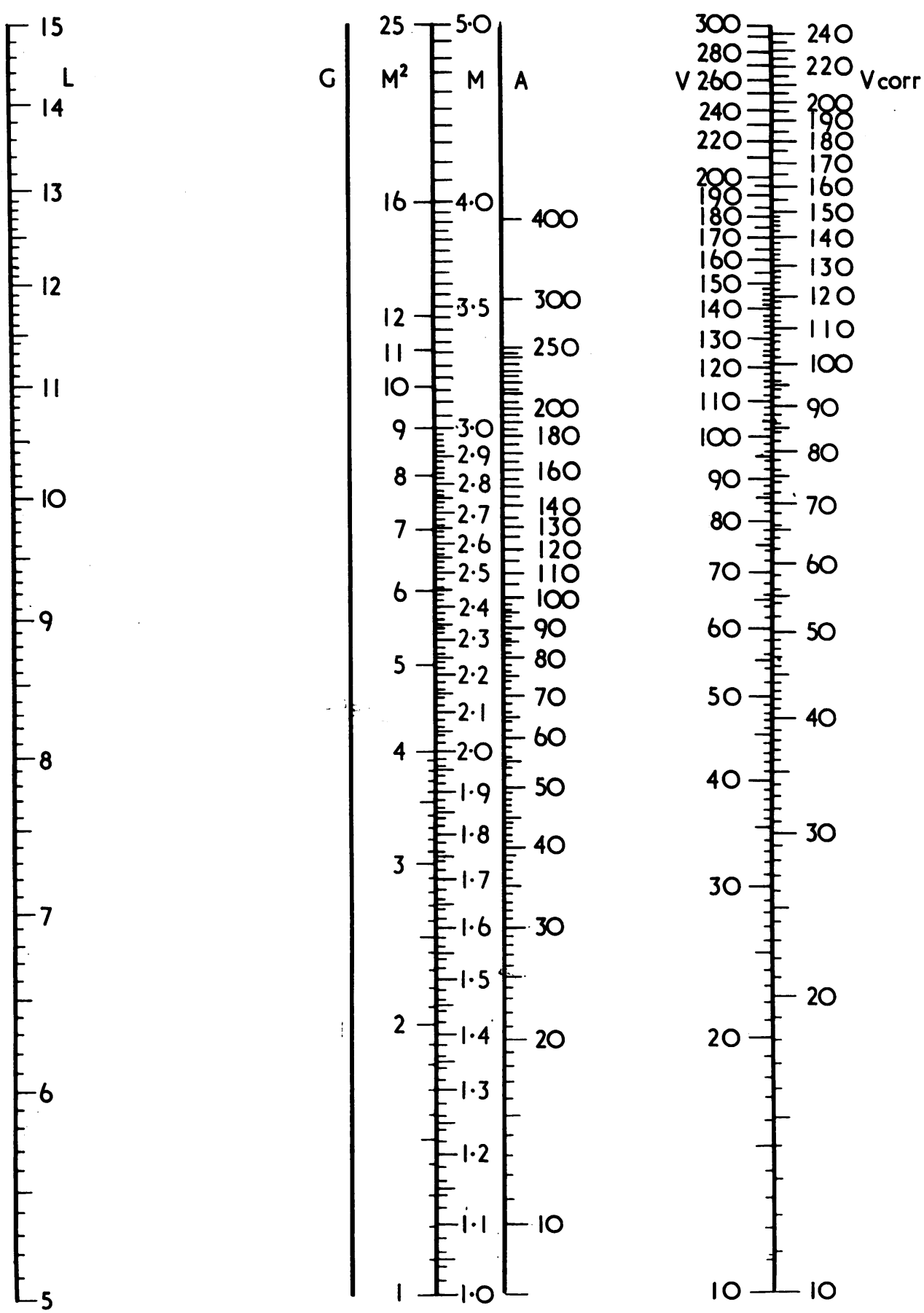

Fig. 1 Nomogram for estimation of left ventricular volume: $L=$ length $(\mathrm{cm})$ as measured from apex to midpoint of aortic valve in $30^{\circ} R A O$ view; $M=$ linear magnification factor; $M^{2}=$ area magnification factor when a grid is used; $A=L V$ planimetered area in $30^{\circ}$ right anterior oblique $\left(\mathrm{cm}^{2}\right) ; V=$ computed volume $\left(\mathrm{cm}^{3}\right) ; V$ corr $=$ corrected volume $\left(\mathrm{cm}^{3}\right)$.

$A$ straight line joining $L$ and $M$ (or $M^{2}$ ) intersects the unscaled line $G$. A second straight line drawn between the point on $G$ and the observed area is extended to $V$ to obtain the computed or corrected volume. 


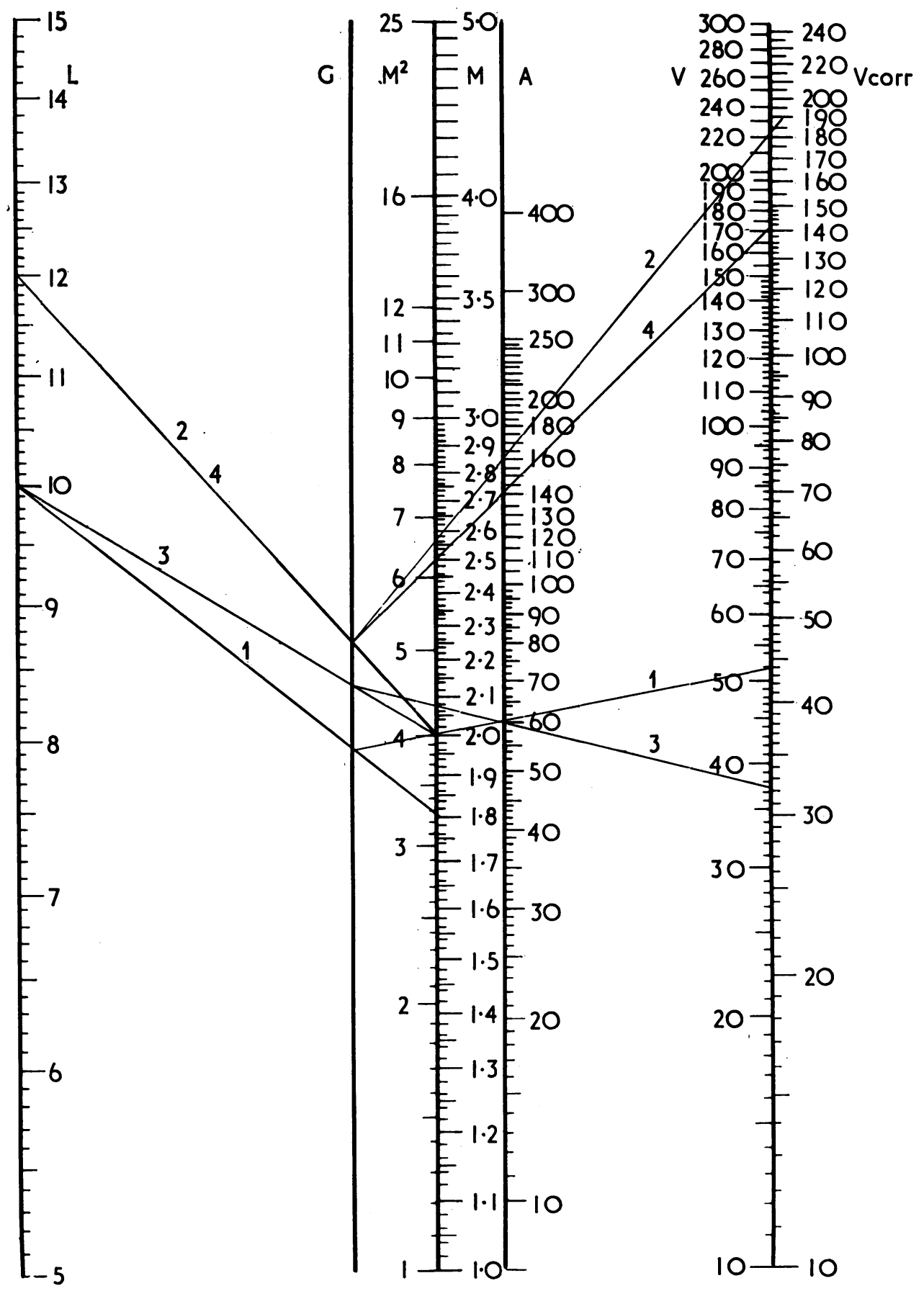

Fig. 2 Illustrated use of nomogram using 4 examples as described in the text (large numbers 1 to 4 ). 
grid area), the value of $M^{2}$ on line $M^{2}$ is used instead of $M$ on line $M$ (example 2 ).

If the length is greater than $15 \mathrm{~cm}$, use half of the value of line $L$ and divide the resultant volume by 2 (example 3).

For left ventricular volumes over $300 \mathrm{ml}$ use half of the value of lines $L$ and $A$ and double the resultant volume (example 4).

\section{Examples}

(1) $\mathrm{L}=10 \mathrm{~cm}, \mathrm{M}=1.8, A=60 \mathrm{~cm}^{2}, \mathrm{~V}=52.3$ (by calculation) and 52.5 (by nomogram). $\mathrm{V}_{\text {corr }}=$ 44.3.

(2) $\mathrm{L}=12 \mathrm{~cm}, \mathrm{M}^{2}=4, \mathrm{~A}=160 \mathrm{~cm}^{2}, \mathrm{~V}=226 \mathrm{ml}$ (by calculation) and $225 \mathrm{ml}$ (by nomogram). $\mathrm{V}_{\text {corr }}=$ $184 \cdot 2$.

(3) $\mathrm{L}=20 \mathrm{~cm}, \mathrm{M}=2, \mathrm{~A}=60 \mathrm{~cm}^{2}$.

$\mathrm{V}$ is found to be $37.5 \mathrm{ml}$ from the nomogram using $\mathrm{L}=10 \mathrm{~cm}, M=2, A=60$. Hence the computed volume when $\mathrm{L}=20 \mathrm{~cm}$ is $37.5 / 2$ or $18 \cdot 8 \mathrm{ml}$. $\mathrm{V}_{\text {corr }}=17 \cdot 1$.

(4) $\mathrm{L}=24 \mathrm{~cm}, \mathrm{M}=2, \mathrm{~A}=280 \mathrm{~cm}^{2}$.

$\mathrm{V}$ is found to be $172 \mathrm{ml}$ from the nomogram using $L=12, A=140, M=2$. Hence the volume when $\mathrm{L}=24, \mathrm{~A}=280, \mathrm{M}=2$, is $172 \times 2$ or $344 \mathrm{ml}$. $\mathrm{V}_{\text {corr }}=280 \cdot 5$.

\section{References}

Dodge, H. T. (1971). Determination of left ventricular volume and mass. Radiologic Clinics of North America, 9, 459-467.

Dodge, H. T., Sandler, H., Ballew, D. W., and Lord, J. D. (1960). The use of biplane angiocardiography for the measurement of left ventricular volume in man. American Heart Fournal, 60, 762-776.

Kasser, I. S., and Kennedy, J. W. (1969). Measurement of left ventricular volumes in man by single plane cineangiocardiography. Investigative Radiology, 4, 83-90.

Kennedy, J. W., Trenholme, S. E., and Kasser, I. S. (1970). Left ventricular volume and mass from single-plane cineangiocardiogram. A comparison of anteroposterior and right anterior oblique methods. American Heart fournal, 80, 343-352.

Snow, J. A., Baker, L. D., Leshin, S. J., and Messer, J. V. (1969). Validation of the single plane cineangiographic determination of canine left ventricular volume. II. Left ventricular dilatation. Federation Proceedings, 28, 517.

Requests for reprints to Dr. F. B. Saksena, Adult Cardiology, Cook County Hospital, 1835 W. Harrison Street, Chicago, Illinois 60612, U.S.A. 